\title{
A PROTEÇÃO DOS DADOS GENÉTICOS E O DIREITO CONSTITUCIONAL À PRIVACIDADE
}

\author{
Ideltrudes Barreto de Menezes Neta ${ }^{1}$ \\ Dimas Pereira Duarte Júnior ${ }^{2}$ \\ Gidelmo dos Santos Fonseca ${ }^{3}$
}

\section{RESUMO}

Este artigo objetiva analisar como o acesso as informações genéticas pode afetar diretamente o direito à privacidade, através de análise em leis e documentos que proíbem o acesso a tais informações. Tal informação deve ser feita de forma cautelosa e sigilosa, o seu uso demasiado poderá acarretar danos irreparáveis a pessoas avaliadas, e como consequência surgir à discriminação.

$\mathrm{O}$ direito à privacidade abarcado no art. $5^{\circ}$ do nosso texto Constitucional possui um caráter positivo dando ao indivíduo o controle de suas informações pessoais, podendo não somente impedir a sua utilização, como também definir quais as informações poderão ser utilizadas.

Palavras-chave: Dados Genéticos; Direito à Privacidade; Discriminação; Informações Genéticas; Proteção.

\section{ACCESS TO WORKER'S GENETIC INFORMATION AND CONSTITUTIONAL LAW PRIVACY}

\begin{abstract}
This article aims to analyze how access to genetic information can directly affect the right to privacy, through analysis of laws and documents that prohibit access to such information. Such information must be made in a cautious and confidential manner, its use too much may cause irreparable damage to people evaluated, and as a consequence, discrimination may arise.The right to privacy covered in art. 5 of our Constitutional text, it has a positive character giving the individual control of his personal information, which can not only prevent its use, but also define which information can be used.
\end{abstract}

Keywords: Genetic data. Right to Privacy; Discrimination; Genetic Information; Protection

\section{INTRODUÇÃO}

\footnotetext{
1 Mestranda em Direitos Humanos pela Universidade Tiradentes. Graduada em Direito pela Universidade Tiradentes. Especialista em Direito do Trabalho e Previdenciário pela Faculdade Guanambi/ba. Advogada. Bolsista da FAPITEC/SE. Email: ideltrudes.menezes@gmail.com

${ }^{2}$ Doutorado em Ciências Sociais: Relações Internacionais pela Pontifícia Universidade Católica de São Paulo PUC-SP. Mestrado em Filosofia Política pela Universidade Federal de Goiás. Graduação em Direito pela Universidade Católica de Goiás. Professor e Pesquisador do Mestrado em Direitos Humanos da Universidade Tiradentes - UNIT/SE. Email: dimas.duartejr@gmail.com.

3 Mestrando em Direitos Humanos pela Universidade Tiradentes. Graduado em Direito pela Universidade Tiradentes. Advogado e Professor. Email: gidelmosf@ hotmail.com.
} 
É imperioso salientar que a importância do tema abordado no presente artigo, já se impõe. O direito à privacidade está assegurando na Carta Magna e deve ser plenamente respeitado e efetivado.

É cediço que os avanços tecnológicos trouxeram enormes benefícios para sociedade, como também trouxe em seu âmago problemas que estão afetando diversas pessoas. O projeto genoma humano adveio desses avanços e trouxe possibilidades que antes eram consideradas remotas, é necessário limites jurídicos-morais para a utilização dos enormes avanços ocasionados pelas ciências biotecnológicas.

Com um simples exame de DNA será possível descobrir predisposições para futuras doenças, trazendo informações de um valor tão relevante, que não só atingirá o ser avaliado, como também toda sua família. A questão que traz angústia e ao mesmo tempo preocupação, é a facilidade de aquisição de informações advindas dos testes genéticos, até porque estas informações possuem um valor grandioso para terceiros, que poderão utilizá-los com fins negativos para a pessoa geneticamente avaliada.

E o pior, com isso vem à tona o desrespeito, a violação a direitos humanos fundamentais, que de certo modo são direitos básicos de qualquer ser. Direitos estes que demoraram anos para serem devidamente reconhecidos.

As leis mencionadas neste trabalho devem ser devidamente respeitadas e efetivadas, para que possamos dizer que os seres humanos estão sendo humanamente protegidos.

Mas, quem especificamente terá acesso a esses resultados, e quem vai controlar a privacidade desses mesmos resultados? Será que as pessoas avaliadas possuem condições psicológicas de receberem essas informações? Será que é ético revelar essas informações?

São perguntas que clamam por respostas de forma imediata, e essas indagações ficam ainda mais grandiosas quando se analisa o direito à privacidade em face dos avanços tecnológicos, e ainda da possibilidade do acesso as informações genéticas. Talvez esses questionamentos busquem respostas através dos valores éticos, entretanto, quando partimos da ideia de uma ética direcionada a profissionais da área médica, nos levamos a crer que esta não seja mais suficiente para enfrentar tantos questionamentos.

O presente artigo será desenvolvido através de uma pesquisa bibliográfica, a partir de materiais publicados em livros, leis, artigos, revistas, reportagens, monografias e teses. Segundo Cervo e Bervian, a pesquisa bibliográfica "constitui o procedimento básico para os 
estudos monográficos, pelos quais se busca o domínio do estado da arte sobre determinado tema", (CERVO; BERVIAN, 2007).

O método utilizado para pesquisa será o qualitativo, este método apresenta características que correspondem as necessidades do estudo em questão, uma vez que a mesma não cabe quantificação, pertencendo ao pesquisador analisar as informações coletadas. Tal método considera o correto entendimento e definição da pesquisa, além dos objetivos da pesquisa como parte dos dados a serem coletados.

Por isso nas linhas a seguir, demonstraremos como surgiu o Projeto Genoma Humano, tendo em vista ser este o projeto que possibilitou a realização dos testes genéticos, além da sua importância para sociedade, dando prosseguimento analisaremos o direito constitucional à privacidade, onde está abarcado e como sua efetivação ajudará na proteção dos dados genéticos, que vem como um terceiro ponto, onde será demonstrado quais leis existem mundialmente sobre o tema, além de casos de violação desta proteção.

\section{O PROJETO GENOMA HUMANO}

No século XX a humanidade viu-se diante de três grandes empreitadas tecnológicas: O Projeto Manhatan, que autorizou ao homem o controle sobre o átomo e sobre a energia nuclear; o Projeto Apollo, que realizou o sonho da humanidade viajar pelo espaço; e o Projeto Genoma Humano, trabalho mundial de laboratórios Europeus, Americanos e Japoneses, que tem como principal objetivo o mapeamento do conjunto de genes do corpo humano, permitindo descobrir a função de cada um deles e seu papel na formação do corpo e das doenças e, segundo alguns doutrinadores, sua responsabilidade na constituição de aspectos antes considerados psicológicos.

O Projeto Genoma Humano é a descoberta do conjunto de genes que constitui cada ser humano. Nelas são também encontradas todas as informações genéticas herdadas. Conceituando assim, Francisco Vieira Lima Neto:

O termo genoma significa um conjunto completo de genes e cromossomos de um organismo, sendo o Projeto Genoma Humano um esforço mundial da pesquisa, com o objetivo de analisar a estrutura do DNA humano e determinar a posição dos $3 \times 109$ pares de bases do genoma humano. (NETO, 2008.p. 30)

Realizar o mapeamento genético, significa trabalhar de forma gráfica sobre o posicionamento dos genes no genoma humano, este processo faz a fragmentação do DNA e cataloga as bases que o compõem e reconstrói sua sequência original. 
As primeiras manifestações atinentes ao Projeto Genoma Humano, são tomadas pelos Estados Unidos em 1984, sendo que o Departamento de Energia (DOE) e o National Institutes of Health (NIH), é que criou o Projeto Genoma Humano. No ano 2000, cinco anos antes do previsto, as primeiras fases do Projeto haviam terminado, seguindo assim para a análise das informações coletadas.

Em um de seus estudos, os cientistas do projeto se isolaram e chegaram a duas posições, a primeira era que com tal projeto não se descobriria o suficiente que justificasse todo o investimento ali feito. Já a segunda posição entendeu que com este Projeto seriam descobertos conhecimentos grandiosos e demasiadamente perigosos que trariam à baila possibilidades de discriminações.

O Brasil integra esse projeto desde 1997, o Projeto Genoma Humano tem seu principal apoio advindo da Fundação de Amparo à Pesquisa do Estado de São Paulo (FAPESP), do Conselho Nacional de Desenvolvimento Cientifico e Tecnológico (CNPq) e do Programa de Apoio ao Desenvolvimento Cientifico e Tecnológico (PADCT). O Projeto Genoma Humano Brasileiro, que gerou a Rede Nacional de Sequenciamento de DNA, hoje possui 25 laboratórios.

Os benefícios que surgem a partir desses novos avanços tecnológicos serão sempre positivos, desde que sejam usados em benefício dos seres humanos, além de como essas informações poderão beneficiar ou ter alguma utilidade na vida de cada ser humano. Para Gisele Echterhoff, as consequências do mapeamento do genoma humano não se restringem apenas aos benefícios. Tais descobertas trazem em seu âmago diversas questões extremamente preocupantes que necessitam da interferência da ética e do direito, (ECHTERHOFF, 2010).

Dentre os possíveis problemas que podem surgir através do mapeamento, cita-se: privacidade das informações genéticas, segurança e eficácia da Medicina Genética e justiça no uso das informações genéticas. Como cita Francisco Vieira Lima Neto por Carlos María Romeo Casabona:

A informação que se poderia obter, como consequência da realização das análises genéticas nas pessoas, suscita alguns problemas relativos a essa informação, a seu acesso e a sua utilização, pois os interesses da pessoa afetada podem entrar em conflito com outros interesses individuais - incluídos os dos familiares biológicos - ou coletivos, relacionados a saúde e à segurança, mas também os de outra natureza, como são os econômicos. Com efeito, o acesso a esta informação dará conhecimento de aspectos muito importantes da pessoa a que se referiram, atingindo de forma muito direta a 
sua esfera intima, mas serão também de grande importância e utilidade para proteger sua saúde e a de sua descendência. (NETO, apud CASABONA, 2008. p. 61)

Importante se faz observar que grande parte dos recursos destinados ao Projeto Genoma Humano, destina-se a financiar debates e reflexões éticas acerca das atividades que serão realizadas pelos cientistas e os reflexos e consequências que trarão para humanidade.

O Instituto Nacional de Saúde e o Departamento de Energia, destinam entre 3\% a 5\% de seus orçamentos anuais para manter um programa chamado de ELSI (Ethical, Legal and Social Issues Program), que tem como principal objetivo patrocinar iniciativas que analisam assuntos éticos, legais e sociais das investigações e intervenções no genoma da espécie humana. Para Francisco Vieira Lima Neto, essa é uma prova de que para os governos e os pesquisadores envolvidos no projeto a reflexão ética deve acompanhar e disciplinar a atividade científica, (LIMA NETO, 2008).

Muitas empresas norte-americanas já analisam aspectos genéticos em testes admissionais, enquanto a Inglaterra já permite que as seguradoras condicionem o valor do prêmio à presença de doenças genéticas. No Estado de Massachusetts já foram relatados 582 casos de pessoas discriminadas em decorrência de suas informações genéticas.

Para Alice Monteiros de Barros somente em casos excepcionais as informações sobre a esfera privada do empregado podem ser acessadas, em especial quando forem relevantes para a execução das funções que serão executadas. (BARROS, 2009).

\section{O DIREITO CONSTITUCIONAL À PRIVACIDADE}

A primeira declaração a mencionar o direito a intimidade foi a Declaração Americana dos Direitos e Deveres do Homem, aprovada em Bogotá em 1948, esse foi o primeiro texto a proteger expressamente a intimidade.

Declaração Universal dos Direitos Humanos (DUDH), estabelece:

Artigo 12: Ninguém será sujeito a interferências em sua vida privada, em sua família, em seu lar ou em sua correspondência, nem a ataques à sua honra e reputação. Todo ser humano tem direito à proteção da lei contra tais interferências ou ataques.

Nossa Carta Magna estabelece em seu art. $5^{\circ} \mathrm{o}$ direito à privacidade.

Art. $5^{\circ}, \mathrm{X}$, - São invioláveis a intimidade, a vida privada, a honra e a imagem das pessoas, assegurado o direito a indenização pelo dano material ou moral decorrente de sua violação". 
Segundo Gisele Echterhoff, o reconhecimento deste direito surge historicamente somente quando a burguesia se universaliza como classe social e o avanço tecnológico aumenta as possibilidades de violação da cidadela da intimidade da pessoa humana, (ECHTERHOFF, 2010).

No século passado o direito à privacidade era restringido à proteção da tranquilidade, tendo em vista que era um nítido caráter individualista, característica esta que era explicita naquela época. Sendo assim, foi iniciada um lenta elaboração do conteúdo do direito à privacidade, uma vez que no século passado este direito ainda não havia se firmado como autônomo. O direito à privacidade foi mais estudado de forma autônoma, após o seu reconhecimento pela Declaração Universal de Direitos do Homem de 1948.

Nas palavras de Jugen Habermas:

Como a crescente liberdade de escolha incentiva a autonomia privada do indivíduo, a ciência e a técnica estiveram até o momento informalmente aliada ao princípio liberal de que todos os cidadãos devem ter a mesma chance de moldar a sua própria vida de maneira autônoma. (HABERMAS, 2010, p 35)

O direito à privacidade pode ser considerado um gênero, do qual possui duas espécies: a intimidade e vida privada. Para Gisele Echterhoff, o direito à privacidade se refere a todas as manifestações da esfera intima, dizendo respeito a todos aqueles costumes pessoais que cabe somente ao indivíduo a escolha de sua divulgação ou não, representando a disposição do cidadão sobre todas as informações a seu respeito. (ECHTERHOFF, 2010)

Já quando se fala de direito à intimidade nos referimos a sua essência, ela é mais interna, restrita, relacionando-se ao íntimo do ser humano. Já a vida privada é menos restrita e mais aberta a terceiros, de acordo com as decisões da própria pessoa.

Para Ariel Salete, o direito à privacidade integra os direitos da personalidade:

As transformações sociais e tecnológicas fizeram com que esse direito passasse a ser mais detidamente analisado, inclusive enquadrado como uma categoria de Direitos Humanos, com a previsão contida na Declaração Universal dos Direitos do Homem, (JÚNIOR, 2016, p 69)

Como diz Jugen Habermas, lesões a direito humano não podem ser reduzidas a infrações às representações axiológicas (HABERMAS, 2010). É notório destacar que o direito à privacidade está atrelado com as informações pessoais de cada indivíduo, dentre estas informações que podem ser acessadas estão os resultados dos testes genéticos. Por isso, quando vem à tona que o empregador utilizou informações sobre o material genético de determinado 
ser, a discussão passa pela intimidade e vida privada, como um aspecto do direito à privacidade.

Além do mais para que haja proteção as dados genéticos, é necessário a efetivação deste direito, ou vice-versa. Digo que um é consequência do outro, até porque caso não haja proteção aos dados, o direito à privacidade será violado.

Um lado positivo da utilização dessas informações servem para beneficiar os seus portadores e familiares, e consequentemente o seu armazenamento em lugares seguros poderá ser um patrimônio que futuramente ajudará a espécie humana. Mas, infelizmente também existe o outro lado, e porque não dizer o lado sombrio de toda a história, o lado negativo, o armazenamento incorreto dessas informações. Sua utilização com objetivos específicos, tal como o econômico trará ofensas a inúmeros direitos fundamentais, entre eles o direito à privacidade dos dados genéticos.

Imperioso se faz mencionar um caso do uso inadequado dessas informações que ocorreu nos Estados Unidos, o caso da Procuradora de Justiça Theresa Morelli. Seu pai teve um diagnóstico da doença de Huntington, mas apesar dela não apresentar nenhum sintoma da doença e de sequer requerer a realização do exame genético, o seu nome foi automaticamente incluído na "lista negra" das seguradoras de saúde do seu país, como uma possível portadora da doença. O possível diagnostico do seu pai foi crucial para ter seu prontuário no banco de dados das seguradoras, ficando assim impedida de acessar qualquer seguro-saúde.

Este é mais um caso de violação ao direito à privacidade. Carlos Maria Romeo Casabona adverte que tais problemas podem afetar a liberdade das pessoas, caso realizem testes compulsórios, como também a intimidade do indivíduo, caso se possibilite o acesso a tais informações a terceiros. (CASABONA, 1999, p. 57).

A necessidade de um consentimento no qual seja informado o seu direito de não saber, além da proteção e confidencialidade das informações advindas dos testes, é algo imprescindível para que não haja a violação de direitos aqui já mencionados. Nas sábias passagens de Jugen Habermas:

Não podemos excluir a possibilidade de casos dissonantes enquanto não pudermos estar seguros de que uma harmonização entre as intenções próprias e alheias está garantida. Em casos de intenções dissonantes, percebe-se que o destino natural e o determinado pela socialização distinguem-se num aspecto moralmente relevante. (HABERMAS, 2010, p. 85). 
É imprescindível limites jurídicos para que se dê um basta no uso e manuseio dessas informações tão pessoais, que podem acarretar ofensas imensuráveis a direitos individuais e garantias fundamentais. E esses limites devem abranger tantos os pesquisadores como a sociedade como um todo.

\section{A PROTEÇÃO DOS DADOS GENÉTICOS: LEIS E CASOS EXISTENTES}

Os avanços tecnológicos, além dos avanços das ciências biotecnológicas trazem um ar assustador ao mundo, o simples fato de uma gota de sangue ou um fio de cabelo ser um dos principais objetos de onde irá se extrair informações pessoais que são altamente relevantes, e que podem atingir a privacidade não só do ser que foi geneticamente avaliado, mas de todos os seus familiares é algo difícil de se entender. Para Jurgen Habermas:

Os desenvolvimentos notórios e temidos da tecnologia genética afetam a imagem que havíamos construído de nós enquanto ser cultural da espécie, que é o "homem", e para o qual não haver alternativas. (HABERMAS, 2010, p 56)

Para Gisele Echterhoff, as características genéticas são permanentes e inalteráveis, (ECHTERHOFF, 2010). O Projeto Genoma Humano possibilitou a realização de testes genéticos, onde serão identificadas aspectos como, a identidade, saúde, herança genética. Ocorre que, não é possível prever as consequências que essa informação poderá resultar tanto para o próprio indivíduo avaliado, como para terceiros que possuem planos específicos e estão interessados nessas informações, tais como empregadores, seguradoras, planos de saúde.

Cumpre salientar que essas informações são de extrema importância e o perigo do seu uso inadequado pode ser devastador. Os cidadãos estão sujeitos e correm o risco de serem julgados em razão dos seus dados genéticos, e isto é a maior preocupação quando se fala do uso demasiado dessas informações. Para Gisele Echterhoff:

As consequências do uso inadequado e abusivo do uso dos dados genéticos poderão ser imensas, pois certamente estes dados, com maior ênfase, serão utilizados para identificar e julgar pessoas. Já se evidenciou que o uso inadequado dessas informações pode acarretar a discriminação de seu portador, a sua estigmatização trazendo-lhe consequências tanto no âmbito familiar, como profissional e social. (ECHTERHOFF, 2010, p 83)

Quando se fala no profissional, existem as possibilidades de discriminação. A descoberta pelo empregador, por exemplo, de uma eventual predisposição para uma futura doença poderá acarretar a exclusão do empregado. Entretanto, essa exclusão não se relaciona com sua falta de aptidão técnica para o cargo ofertado e sim pela possibilidade de adquirir uma doença que somente aparecerá num futuro remoto. 
Essa é uma da nova forma de discriminação que vem surgindo em razão dos grandes avanços científicos. Um trabalhador poderia não ser contratado, pelo simples fato de apresentar em seu DNA a probabilidade que no futuro nem tão certo ainda poderia manifestar doenças ou até mesmo comportamentos estranhos que podem ou não virem a se manifestar, visto que alguns cientistas vêm defendendo a hipótese de que existem genes responsáveis por determinados comportamentos, virtudes e defeitos. Como enfatiza Tom Wilkie:

Discriminação maior ainda ocorreu no mercado de trabalho. Negros que tinham o traço falciforme, mas não a doença, foram recusados em empregos em companhias áreas e até impedidos de ingressar na Academia da Força Aérea dos Estados Unidos em razão da crença equivocada de que seu sangue reagiria mal as baixas pressões do ar (e portanto da concentração do oxigênio) experimentadas quando se atingem altitudes elevadas em aviões comerciais ou militares. (WILKIE, 1993.p. 125)

Para José Claudio Monteiro de Brito Filho nas relações de empego existe um ambiente propício e ideal para quem vai discriminar, dada à vulnerabilidade do trabalhador, visto que isto decorre da necessidade que o empregado tem que trabalhar para sobreviver, garantindo assim a subsistência também da sua família, (BRITO FILHO, 2002)

Sendo assim enfatiza Tom Wilkie:

$\mathrm{Na}$ década de 70, muitos estados Americanos instituíram programas de testagem em massa para a detectação de anemia falciforme que, ao mesmo tempo em que fizeram muito pouco para ajudar os atingidos pela doença, resultaram em discriminação contra pessoas saudáveis que eram casualmente portadoras de uma única cópia do gene. Embora não fossem em absoluto afetadas pela doença, algumas pessoas foram recusadas em empregos ou impedidas de fazer seguros de saúde em razão de sua constituição genética. (WILKIE, 1993. p. 117)

Independentemente do modo de seleção adotado por cada grupo empresarial deve existir uma limitação para que não sejam ofendidos os direitos dos candidatos, principalmente seu direito à privacidade, nestes casos o que deve prevalecer é a ética. Para Alice Monteiros de Barros somente em casos excepcionais as informações sobre a esfera privada do empregado podem ser acessadas, em especial quando forem relevantes para a execução das funções que serão executadas. (BARROS, 2009). Já a exigência de testes genéticos para a arrecadação de informações genéticas nos contratos de emprego não há razoabilidade, porque é inútil, se tem por fim escolher o melhor candidato ou até mesmo como forma de evitar que o empregado se sujeite a condições ambientais desfavoráveis e assim possibilite o desenvolvimento de doenças. 
Logo, o que pode vir a acontecer é a proliferação da exigência de testes genéticos e a partir daí a produção de discriminação do candidato por traço genético.

O caso de Terri Seargeant, foi relatado pelo Jornal O Estado de São Paulo no ano 2000, uma falha genética a tornou vulnerável a paradas respiratórias. A descoberta pôde salvar a sua vida, mas perdeu seu emprego, a empregada foi demitida por ser considerada um risco. Segundo o referido jornal, este foi o primeiro caso de discriminação genética nos Estados Unidos.

Tal caso demonstra a violação ao direito à privacidade de forma explicita. Além da discriminação sofrida pelo ser ali avaliado, não houve o cuidado e o sigilo com a informação obtida. E é essa a maior preocupação, os seres com doenças genéticas estão sendo tratados como coisas, objetos que devem ser descartados. Por isso a importância da cautela no uso das informações advindas dos testes genéticos e da necessidade de esclarecimento ao ser avaliado, destacando ao mesmo o porquê da realização do teste, e principalmente o sigilo do resultado. Devendo ainda o ser avaliado decidir se quer ou não realizar o mesmo.

Carlos María Romeo Casabona cita quais seriam os objetivos dos empregadores na realização de tais testes:

a) Realizar uma seleção negativa, a qual tem como proposito a não contratação de candidatos em que tivessem sido diagnosticadas doenças de potencial manifestação posterior ou aquelas de predisposição de origem multifatorial, ou seja, nas quais diversos fatores influenciaram no desenvolvimento da doença, entre eles o meio ambiente, seja este relacionado ou não com as condições de trabalho;

b) Realizar uma seleção positiva, a qual tem como proposito a escolha de trabalhadores mais aptos para um meio ambiente de trabalho determinado "de acordo com características genéticas (maior resistência física, ao sono, a determinados agentes tóxicos, cancerígenos, etc.) (CASABONA, 1999, p 74).

É cediço que existe diversas leis no ordenamento jurídico brasileiro sobre discriminação. Mas, em relação a discriminação genética existem apenas projetos de lei, PL 4900/99 que tramita perante o Congresso Nacional, mas que nunca foi sequer posto em votação. Além da PL de origem do Senado Federal que recebeu o no 149/97, no qual trata as discriminações genéticas como condutas delituosas da área criminal, imputando ao agente pena privativa de liberdade.

Art. $6^{\circ}$ recusar, negar ou impedir inscrição em concurso público ou em quaisquer outras formas de recrutamento e seleção de pessoal com base em informação genética do postulante, bem como, com base em informações dessa natureza obstar, impedir, o acesso ou permanência em trabalho, 
emprego, cargo ou função na Administração pública ou iniciativa privada. Pena: detenção de um mês a um ano, e multa.

Para Francisco Vieira Lima Neto:

Tal dispositivo protege a pessoa humana não só no momento da sua nomeação, mas também quando da sua inscrição em um concurso público, constituindo-se um exemplo claro de que a discriminação genética acaba vilipendiando o direito à igualdade, manifestando aqui como direito a concorrer em igualdade de condições a um cargo público. (LIMA NETO, 2008, p 123).

No Brasil, houve dois casos noticiados de discriminação genética, ambos ocorreram no esporte, um na Confederação Brasileira de Vôlei Feminino em 2004, onde as atletas foram submetidas a exames genéticos para verificar predisposições para anemia falciforme. O teste de uma das atletas deu positivo e a mesma fora excluída da seleção. Ao ser questionada sobre a exclusão da atleta, a confederação disse que o traço representaria um risco a integridade física e ao desempenho em esportes competitivos.

A outra aconteceu na Confederação Brasileira de Futebol em 2010, os exames feitos nas atletas buscavam identificar condições físicas que exigissem algum tipo de assistência em saúde, além de atestar condições adequadas para as disputas. O exame de uma das atletas deu positivo para o traço falciforme, e então com grande semelhança com o caso acima, a mesma fora dispensada da seleção brasileira de futebol. A confederação em sua explicação informou que a atleta poderia seguir com sua carreira, mas não poderia jogar na altitude. Uma nobre desculpa, para quem ia enfrentar uma partida no Equador.

Fato a ser levado em consideração foi a forma como ambas as confederações revelaram os resultados dos testes, sem assegurar o direito à privacidade, além de não dispor em sua equipe técnica profissionais qualificados que pudessem oferecer o aconselhamento genético. Informações pessoais não devem ser levadas a público de qualquer maneira, as atletas possuíam direito de serem consultadas antes da realizações dos exames, o que não ocorreu. Ambos os casos envolveram atletas mulheres, que foram afastadas de suas funções com a justificativa de caráter preventivo. As eliminações não tiveram fundamentos justificáveis, que sequer levaram em conta a trajetória anterior de ambas nas competições as quais participaram.

Tom Wilkie afirma:

Qualquer aplicação de testes destinada simplesmente a compilar números relativos à incidência de uma doença tem de se fundar num equilíbrio entre os interesses dos indivíduos a serem testados, ou com possibilidade de pertencer ao mesmo grupo que os testados, e o interesse ainda mais amplo da sociedade 
pelo conhecimento a ser assim adquirido. Em caso de conflito, a maioria das sociedades tende a dar maior ênfase aos interesses dos indivíduos, ao menos que se possa demonstrar que, em dado caso, o conhecimento em questão é de extrema importância para a coletividade. $\mathrm{O}$ valor a ser atribuído aos direitos dos indivíduos parece ser ainda maior quando o que está em jogo é algo tão pessoal e intimo como a sua constituição genética. (WILKIE, 1993.p. 127)

Um dos documentos mais destacados sobre o tema é a Declaração do Genoma Humano e dos Direitos Humanos adotada pela Assembleia Geral da UNESCO em 1997. Conforme relata em seu art. $6^{\text {o: }}$ "ninguém será sujeito à discriminação baseada em suas características genéticas que visem infringir os direitos humanos, as liberdades fundamentais ou a dignidade humana". Além do seu art. $9^{\circ}$ que trata da privacidade e confidencialidade das informações obtidas através dos testes genéticos.

Pode-se ainda citar que a Organização Mundial de Saúde (OMS) em um dos seus encontros sobre assuntos éticos na genética médica no ano de 1997, aprovou um guia que determinava e reafirmava os princípios éticos de relevância para a medicina. Foi aprovado naquele ano o Guia Sobre Assuntos Genéticos na Medicina Genética e nos Serviços Genéticos.

A Declaração da ONU sobre Utilização do Progresso Científico e Tecnológico no Interesse da Paz e em Benefício da Humanidade, proclamada pela Assembleia Geral em 1975 preceitua em seu item 2:

Todos os Estados tomarão medidas apropriadas a fim de impedir que os progressos científicos e tecnológicos sejam utilizados, particularmente por órgãos estatais, para limitar ou dificultar o gozo dos direitos humanos e das liberdades fundamentais da pessoa consagrados na Declaração Universal de direitos Humanos, nos Pactos Internacionais de direitos Humanos e em outros instrumentos internacionais pertinentes.

São vastos os documentos oficiais que tentam impedir o acesso as informações genéticas das pessoas, mas na prática o uso desses documentos são escassos. Na relação trabalhista é o meio mais propicio de ocorrer a invasão ao direito à privacidade, uma vez que são necessários testes admissionais para o ingresso do empregado no seu posto de trabalho. Mas, será que a utilização dessas informações são éticas? E os empregados, será que eles querem saber ou tem condições psicológicas de receber aquelas informações, naquele momento?

Como dito, são perguntas que clamam por respostas imediatas. Vê-se a necessidade da existência de limites éticos e jurídicos nos referidos casos. Para Jugen Habermas: 
Impõe-se a questão de saber se a tecnização da natureza humana altera a auto compreensão ética da espécie de tal modo que não possamos mais nos compreender como seres vivos eticamente livres e moralmente iguais, orientados por normas e fundamentos. (HABERMAS, 2010, p 57)

Nos Estados Unidos existem Estados que possuem lei sobre o tema, desde 1994. Em 2001 foi ajuizada na justiça federal no Estado de IOWA, uma petição contra a empresa Burlington Northen Sante Fé, onde foi requerido a ré que cessasse a convocação para serem submetidos a testes genéticos de empregados que relataram está sofrendo de certa síndrome provocada por agentes deletérios no cromossomo 17 (síndrome do túnel carpal), assim como suspender qualquer sanção que estivesse a ser aplicada aos que não se apresentavam para o exame. O Congresso dos Estados Unidos aprovou em 2008, lei federal que proíbe toda e qualquer discriminação baseada em informações genéticas, principalmente por parte de empregadores e companhias de seguro.

Já na Europa, um dos documentos que merece destaque é a Convenção de Oviedo, um dos nomes da Convenção sobre Direitos Do Homem e a Biomedicina, de 1997, cujo art. 11 garante a não-discriminação de uma pessoa em razão de seu patrimônio genético.

Artigo 11. ${ }^{\circ}$ É proibida toda a forma de discriminação contra uma pessoa em virtude do seu património genético.

Artigo $12 .^{\circ}$ Não se poderá proceder a testes predictivos de doenças genéticas ou que permitam quer a identificação do indivíduo como portador de um gene responsável por uma doença quer a detecção de uma predisposição ou de uma susceptibilidade genética a uma doença, salvo para fins médicos ou de investigação médica e sem prejuízo de um aconselhamento genético apropriado.

É preciso ter um enorme cuidado quando falamos do uso da informações genéticas. Os seres avaliados, em muitos casos não possuem apoio psicológico quando do recebimento dessas informações. As pessoas devem guardar sigilo, além de serem devidamente cautelosos, ao serem sabedores dos resultados, principalmente os empregadores, planos de saúde, seguradoras. Ocorre que como vemos claramente não é o que vem acontecendo.

Apesar de existirem leis em todo mundo que de uma certa forma proíbe o acesso as informações advindas da realização dos testes genéticos, muitos casos que já foram judicializados, principalmente nos EUA, onde as leis são bastante especificas estão acontecendo de forma explicita.

A privacidade dos seres avaliados está sendo afetada. Os direitos humanos devem ser devidamente efetivados, o simples fato de possuir predisposição para doenças não pode e nem 
deve ser empecilho para se conseguir um emprego, ou contratar um plano de saúde, por exemplo. Ser discriminado por algo que nem pode acontecer em futuro remoto, além de ter sua privacidade invadida, não parece ser razoável.

\section{CONCLUSÃO}

Fica evidenciado que é necessário cautela no uso das informações genéticas e que as promessas que virão decorrente dos avanços biotecnológicos traz consigo uma imensidão de possibilidades.

O simples fato de fazer um exame de DNA e saber que será acometido por uma possível doença causa preocupação aos indivíduos geneticamente analisados. Os testes genéticos devem ser feitos de forma cautelosa e principalmente sigilosa, tendo em vista que as informações obtidas através deles podem ser relevantes e ao mesmo tempo angustiantes em alguns casos.

Destaca-se que o direito constitucional à privacidade deve ser devidamente respeitado, o uso demasiado das informações genética pode acarretar violação a direitos e garantias fundamentais que demoraram anos para serem efetivados. No Brasil principalmente, como verificado existe uma lacuna quando o assunto é acesso a informações genéticas ou discriminação genética. Nota-se com os casos registrados que apesar de existir legislações que tratem sobre o tema, é necessário uma análise mais abrangente, onde seja desenvolvido pontos que lhes tragam melhora, para que assim se possa obter mais êxito.

É notório que precisamos estabelecer limitações ao acesso das informações genéticas, além de tornar efetivo o direito à privacidade das informações, e como consequência lograr êxito quando falamos da proteção dos dados genéticos.

Portanto, deve-se ficar atento a esta era da informação e dos grandes avanços tecnológicos, o mundo necessita se adequar as mudanças. As pessoas possuem o dever da informação e do livre esclarecimento, pois são elas as únicas detentoras do querem saber ou fazer com essas informações.

Com os dados que expostos aqui, fica demonstrado que é necessário muita cautela quanto as informações advindas dos testes genéticos. A sua proteção é peça imperiosa para efetivação do direito à privacidade ou vice-versa.

\section{REFERÊNCIAS}


BARROS, Alice Monteiro. Proteção a intimidade do empregado. São Paulo: Ltr, 2. ed., 2009.

CASABONA, Carlos Maria Romeo. Do gene ao Direito: sobre as implicações jurídicas do conhecimento e intervenção no genoma humano. São Paulo: IBCCrim, 1999.

CERVO, Amado Luiz; BERVIAN, Pedro Alcino. Metodologia Cientifica. São Paulo: McGraw-Hill do Brasil, 2007.

Constituição da República Federativa do Brasil. Aprovada em 05 de outubro de 1988. Disponível em: http://www.planalto.gov.br/ccivil 03/constituicao/ConstituicaoCompilado.htm. Acesso em 10 de novembro de 19.

Convenção sobre Direitos Do Homem e a Biomedicina, de 1997, disponível em $<$ http://gddc.ministeriopublico.pt/sites/default/files/documentos/instrumentos/convencao_prote cao_dh biomedicina.pdf $>$. Acesso em 17 de Janeiro de 2020.

Declaração dos Direitos do Homem e do Cidadão, adotada pela Assembleia Nacional Constituinte em 26 de agosto de 1789. Disponível em: <http://www.direitoshumanos.usp.br/index.php/Documentosanteriores\%C3\%A0cria\%C3\%A\% C3\%A3o-da-Sociedade-das-Na\%C3\%A7\%C3\%B5es-at\%C3\%A91919/declaracao-dedireitosdo-homem-e-do-cidadao-1789.html>. Acesso em 10 de novembro de 2019.

Declaração Universal dos Direitos Humanos, adotada pela Assembleia Geral das Nações Unidas em 10 de Dezembro de 1948. Disponível em < https://nacoesunidas.org/direitoshumanos/declaracao/>. Acesso em 17 de Janeiro de 2020.

Declaração do Genoma Humano e dos Direitos Humanos, adotada pela Assembleia Geral da UNESCO $\quad$ em $1997 . \quad$ Disponível em <https://unesdoc.unesco.org/ark:/48223/pf0000122990_por>. Acesso em 17 de Janeiro de 2020.

A Declaração da ONU sobre Utilização do Progresso Científico e Tecnológico no Interesse da Paz e em Benefício da Humanidade, proclamada pela Assembleia Geral em 1975. Disponível em< http://www.dhnet.org.br/direitos/sip/onu/bmestar/dec75.htm>. Acesso em 17 de Janeiro de 2020.

ECHTERHOFF, Gisele. Direito à Privacidade dos Dados Genéticos. Curitiba: Juruá, 2010

FILHO, José Claudio de Monteiro de Brito. Discriminação no trabalho. São Paulo: Ltr, 2002.

HABERMAS, Jurgen. O Futuro da Natureza Humana. São Paulo: wmf Martins fontes, 2010 .

JUNIOR, Ariel Salete de Moraes. Acesso as Informações Genéticas do Trabalhador: Discriminação Genética e o Livre Consentimento Esclarecido. Curitiba: Juruá, 2016.

LACOMINI. Vanessa. Propriedade Intelectual e Biotecnologia. Curitiba: Juruá, 2009. 
MYSZCZUK, Ana Paula. Genoma Humano: Limites Jurídicos à sua Manipulação. Curitiba: Juruá, 1 ed, 2005.

NETO, Francisco Vieira Lima. O direito de não sofrer discriminação genética. Rio de Janeiro: Lumen Juris, 2008.

Projeto de lei 4900/99, disponível em $<$ https://www.camara.leg.br/proposicoesWeb/fichadetramitacao?idProposicao=21202 >. Acesso em 17 de Janeiro de 2020.

Projeto de lei 149/97, disponível em <http://www.ghente.org/doc juridicos/pls149.htm>. Acesso em 17 de Janeiro de 2020.

ROMITA, Arion Sayão. Direitos fundamentais nas relações de trabalho. São Paulo: Ltr, 4. ed., 2012.

SARLET, Ingo Wolfang. A Eficácia dos Direitos Fundamentais. Porto Alegre: Livraria do Advogado, 2006.

SILVEIRA, Vladmir Oliveira; ROCASOLANO, Maria Mendez. Direitos Humanos, conceitos, significados e funções. São Paulo: Saraiva, 2010.

WATSON, James D. A dupla hélice: Como descobri a estrutura do DNA. Rio de janeiro: Zahar, 1. ed., 2014.

WILKIE, Tom. Projeto genoma humano. Rio de janeiro: Jorge Zalar editor, 1993.

$<$ http://www.scielo.br/scielo.php?pid=S010373312007000300006\&script=sci_abstract\&tlng=p t $>$. Acesso em 18 de Novembro de 2019.

<https://acervo.estadao.com.br/pagina/\#!/20000920-39054-spo-0011-ger-a11-not $>$. Acesso em 13 de Janeiro de 2020.

$<$ http://www.arsalentejo.minsaude.pt/utentes/ces/Documents/Conven\%C3\%A7\%C3\%A30\%20 de\%20Oviedo.pdf $>$. Acesso em 13 de Janeiro de 2020.

$<$ https://www.scielosp.org/article/physis/2015.v25n3/729-751/>. Acesso em 17 de Janeiro de 2020. 